\title{
A Review of Implicit Memory with Gender Stereotype
}

\author{
Yi Lin ${ }^{1, *}$ \\ ${ }^{1}$ University of California, Davis
${ }^{*}$ Corresponding author. Email: yillin@ucdavis.edu
}

\begin{abstract}
Individuals with implicit memory have an unconscious mind and behavior, which is related to their experience and activity in reality. Past research revealed how implicit thought interacts with other factors in our lives. There are many aspects of gender stereotypes and gender differences that have been linked in previous studies. The purpose of this review is to examine gender stereotypes' relationship with occupational, academic, and personal characteristics. Many studies have demonstrated why gender stereotypes occur and how they occur based on the diversity of the environment. Researchers collected statistical data, interviewed participants, and performed laboratory experiments. Academic stereotype with gender stereotype is that males and females do not participate in computer science equally. Occupational stereotypes occur in workplace biases during job interviews. For the autobiographical experience with gender stereotype display, both males and females are affected by their personal experiences and judgments by society. In addition, the family is also a significant factor to be considered. In general, these studies have two major reflections on gender stereotypes. In one sense, people are aware there is a gender stereotype when they confront different gender dominance levels. Gender stereotypes don' t perform strongly when there isn't a clear boundary between male and female ability in their gender roles. One exception is that stereotypes associated with positive and negative statements, which could be their self-definition associated with encounter situations.
\end{abstract}

Keywords: Gender stereotype, Gender difference, Implicit.

\section{INTRODUCTION}

Past research has shown that gender stereotypes are formed mainly due to society's transformation. Social structure not only indicates different classes within society but also suggests many aspects that are related or influenced. The term "gender stereotype" describes implicit reactionary thinking or subconscious thinking based on gender.

Occupational stereotypes often combine gender stereotypes, with men and women unconsciously applying for their "right jobs" to their roles. In simple terms, a male who does a male's job or a female who does a female's job is the right job. In given major fields of study, people have observed that males tend to be more successful and have more leadership skills than females [1-3]. It is a stereotype that male and female students have different strengths in school subjects. For example, a male is good at math, physics, and engineering. Women are more deeply emotional than men, so their skill at writing and drawing is stronger. Examples like these are stereotypes in academic performance. Male and female are different, but not easy to categorize a person's ability in a given thing because people can develop new things [4-6]. An autobiographical experience relating to gender stereotypes. A combination of factors including parenting style, child education, and social environment [7, 8]. Job advertisements with wording stereotypes have an impact on gender equality in work selection and occupations [1]. Where personal opinion varies caused by gender differences [9]. Parental roles play an important part in children's gender roles [10]. A happy memory in our life script occurs frequently when recalling our memory [11]. This finding has explored the self-system concerning autobiography experience, and current goal [12]. The social structure model has found the gender difference remains constant in long progress, genetically and socially [13]. Personal belief plays a role rather than agreement with personal stereotype and prejudice was one of the aspects being discovered [14]. The studies found that gender stereotypes are not favorable to change since intergroup communication was one of the reasons adding challenge to it [15]. The stereotype is systematically over time. The study suggested that stereotypes mix such as competence with low warmth, and competition with high warmth [16]. 
A few limitations are beyond the control of the experimenter. For instance, people have a historical or cultural background, and gender inequality is a national issue. Other limitations were considered as latent variables. Stereotypes have a wide range of meanings. As an illustration, perception of stereotype is affected by the reason for the view, as well as individual differences. In other words, a positive stereotype refers to a positive description of a person's characteristics, while a negative stereotype associate with negative terms and biases [10, 17-19]. However, the implication with a person's positive and negative stereotypes often mix. Generally, gender stereotype is viewed as a negative term. The goal of this article is to discuss gender stereotypes objectively by elaborating on the different aspects. This review shows how gender stereotypes interact with occupational bias, academic performance on gender, and autobiographical experience.

\section{METHOD}

In developing this literature review, three main aspects have a relationship with our research direction. In this review, gender stereotype has play role in academic, occupations, social, and individual.

Some databases were used in this literature review: Google Scholar, American Psychology Association (APA), and other sources came from the university library. The search fields for articles from 2000 to 2021. The searching focused on gender stereotypes and implicit cognition, which are restrictedly connected to our titles. The databases were searching for the following phrase: gender stereotype, workplace bias, job employment bias, gender difference, academic performance, positive or negative gender stereotype. After the process of removing and selecting, there are 17 relevant articles included in this literature review.

The following restrictions able to select and search suitable references base on the purpose of this review:

(1) Only followed the APA research guideline can be utilized,

(2) Only available articles, full text, peer review, and published in English can be used,
(3) The studies must include original results,

(4) The article should use reliable, scientific, professional methods to investigated participants, and should be organized statistically.

(5) The focus of the study should be on gender and indicated how gender stereotype has a relationship between academic performance, occupational conditions, autobiographic experience, and social expectation.

\section{RESULT}

Research studies about academic, occupational, and autobiographic experience play important role in gender stereotypes because most people face more life obstacles in these three filed.

A majority of this article focuses on factors that have an impact and relation to gender stereotype formation. The study found that there is a relationship between gender stereotypes and occupational conditions. Despite job employment requirements, the studies generally explored how workers are being treated in their given careers. A study has 1493 participants, and randomly assigned tests in males and females [1]. Similar to another study have common occupational conditions either male-dominated or female-dominated. The conclusion from these two studies are male-dominated job contained greater masculine wording than femaledominated jobs advertisements. The data shown $\mathrm{P}$ value less than 0.05 is statically significant. A study by Morris and Deshon (2002) has a slight difference from Gaucher and Friesen (2011) in that gender dominating was not complementary, it could be integrated without clear boundaries $[1,2]$. In another situation, the study focus on how gender stereotype has an impact on females' gender identity and discrimination [3]. This study concludes that women have less likely engaged in the course compare to men. Men are more likely to have leadership behavior than women according to task information. However, when task information is unique, women and men have no differences. A summary of gender stereotypes with occupational stereotypes after reviewing the literature is given in Table 1.

Table 1. Summary review of occupational stereotype study

\begin{tabular}{lll}
\hline Author/s and years & Participants & Occupations \\
\hline Danielle and Justin (2011) & $\mathrm{N}=1493$ & $\begin{array}{l}\text { Male-dominated occupations and female-dominated occupations have a connection } \\
\text { with wording advertisement; advertisement favorable in male's wording }\end{array}$ \\
Danielle and Justin (2011) & $\mathrm{N}=3640$ & $\begin{array}{l}\text { Male and female-dominated faculties (engineering vs. art; more masculine wording in } \\
\text { male-dominated faculties than female-dominated faculties) }\end{array}$ \\
Scott and Richard (2002) & Undergraduate, working adults & $\begin{array}{l}\text { Male-dominated jobs and female dominated jobs show numbers of gender influenced } \\
\text { Integrated jobs }\end{array}$ \\
Madeline and Michelle (2005) & $\mathrm{N}=61$ (43 women and 18 men) & Male have more engagement than women
\end{tabular}

Gender stereotypes also display in academic performance. These articles from the previous researcher have found some relationship between academics and stereotypes. The studies have answered this question "Will people unconsciously have stereotypic thoughts toward gender while learning at school? And how do 
people show their discrimination?" The article published by Span Cheryan et al. (2009), study one has demonstrated that students who were not computer science majors when distributed in stereotypical conditions act differently compare to non-stereotypical conditions [4].

Study 3 from Cheryan's article has shown different results for females less interested in computer science rather than men while placing in stereotypic conditions [4]. However, no gender difference in a non-stereotypic environment. Another study published by Huy Phuong Phan (2009) has shown that the ratio of female and male attendance in a class has direct and indirect relation with gender bias [5]. In this study, the researcher has found that there are indirect and direct relations between gender differences of academic performance between self systems, self-esteem, self-efficacy, deep processing, effort, hopelessness. Furthermore, a study published by Paul G. Davis et al. (2002) has concluded that gender difference display on males and females through a difficult math test [6]. The study has shown women underperformance of math tests in stereotypical conditions compare to those women not encounter with stereotypical conditions. Even though males and females received the same stereotyped impact, females perform worse than males in this math test base on the expectation from the researcher.

In general, four of these studies found that gender stereotypes did present in academic circumstances. People implicitly have biases base on gender ratio, performance, grade during class time. A summary of gender stereotypes with academic performance after literature reviewing is given in Table 2 .

Table 2. Summary review of academic performance

\begin{tabular}{|c|c|c|}
\hline Author/s and years & Participants & Conditions \\
\hline $\begin{array}{l}\text { Sapna et al. (2009) } \\
\text { Study1 }\end{array}$ & $\begin{array}{l}\mathrm{N}=52 \text { (Student who were not } \\
\text { computer science majors) }\end{array}$ & $\begin{array}{l}\text { Significant environmental interaction with the } \\
\text { stereotype, favor in male but not female }\end{array}$ \\
\hline $\begin{array}{l}\text { Sapna et al. (2009) } \\
\text { Study3 }\end{array}$ & $\mathrm{N}=85$ (62 women) & $\begin{array}{l}\text { Male preferred non-stereotype working } \\
\text { environment than female }\end{array}$ \\
\hline $\begin{array}{l}\text { Huy Phuong Phan } \\
(2009)\end{array}$ & $\begin{array}{l}\mathrm{N}=290 \text { (university students, } 178 \\
\text { females, } 112 \text { males) }\end{array}$ & $\begin{array}{l}\text { Academic performance in the course Analysis } \\
\text { relation with self-esteem and deep processing }\end{array}$ \\
\hline Paul et al. (2002) & $\begin{array}{l}\mathrm{N}=54 \text { (undergraduate, } 29 \text { men, } \\
25 \text { women) }\end{array}$ & $\begin{array}{l}\text { men are more likely to perform better than women } \\
\text { in math test }\end{array}$ \\
\hline
\end{tabular}

In addition, there is another probability not only has a relationship between gender stereotypes but also influences gender stereotypes simultaneously. The article has shown that a person's life experience, parent expectation, the social expectation has influenced an individual's perspective on gender. Study one pick sample randomly with participants 1485 in total [7]. Study one shows that people within the most positive event, happier in young adulthood. Whereas, when people are aged tend to be more negative events occur. And gender difference also display in the study, which women has traumatic later than men around 3.02 years. Study two split the sample, not in balance, which 87 females and 16 males. The difference between these two studies, which study two asked participants to share what kinds of expectations they have from others or by themselves previously. To be noticed, the temporal order of the events consider an important issue between age and gender.

Another article has demonstrated that gender stereotype might depend on how early life scripts link with this person's mind[8]. The researcher asked participants to rate their life events positive or negative, or only explored the single event in study two. Study one and Study two both effectively show how people presented negative more than positive when recalled their memory. Females scores higher on the CES for negative events than did males, which emphasis female tends to view past event negatively as central identity. Furthermore, after replication, study two has a similar result with study one. The result has shown, (1) females have higher CES scores than males, (2) Kerry voters have significant higher CES scores than the Bush voters for the negative evens, (3) the current study has restrictions and limitations discovered the relation between gender and valence due to less balanced in gender proportion, (4) the current study for gender difference occurred regardless of even valence.

In general, the studies have explored and researched on social effects, cultural differences, environment have an impact on gender differences. Even though most of these findings given by table 3 used a large female sample size compared to males, the result has listed many factors from the mental process and 
memory retrieval overall are based on the researcher's expectation. A summary of gender stereotypes with a person's experience after literature reviewing is given in Table 3.

Table 3. summary review of autobiographic experience and social expectation

\begin{tabular}{|c|c|c|}
\hline Author/s and years & Participants & Autobiographic experience/social expectation \\
\hline $\begin{array}{l}\text { Dorthe and David } \\
\text { (2004) Study1 }\end{array}$ & $N=1485$ & $\begin{array}{l}\text { Life script } \\
\text { Interview and respondent }\end{array}$ \\
\hline $\begin{array}{l}\text { Dorthe and David } \\
\text { (2004) Study2 }\end{array}$ & $\mathrm{N}=103$ (87 females) & Shared expectations of an ordinary life course \\
\hline $\begin{array}{l}\text { Adriel Boals (2010) } \\
\text { Study1 }\end{array}$ & $\mathrm{N}=170$ (98 females) & $\begin{array}{l}\text { Rate positive and negative events in their life; Using a } \\
\text { single event to explore the difference in memory }\end{array}$ \\
\hline $\begin{array}{l}\text { Adriel Boals (2010) } \\
\text { Study2 }\end{array}$ & $\mathrm{N}=111$ (52 males) & It is a more emotional and important event of person's life \\
\hline
\end{tabular}

\subsection{Occupational stereotypes}

Why gender stereotypes occur in the workplace Historically, few aspects have influenced gender stereotypes. First, social and parental expectations toward children and teenagers have changed their selfdetermination unconsciously. Secondly, social and parenting expectations have little effect on a person's selfevaluation, which is determined by how they define themselves in social groups. To fit in society, a person should try to avoid misbehavior and do the right thing. However, the question is what standard is considered right.

\subsubsection{Employment and gender bias}

Gender stereotypes and employee acceptance are related. Workplace stereotypes, employment rates, and sex distributions within careers impact gender bias. According to research by Heilman and Haynes, people's brain functions are categorized by memory and impression. As a result, the study found that males and females respond differently to specific types of words provided by the researchers. In this example, Heilman and his partner observed that males tend to display stronger leadership characteristics than females [3]. Heilman and Haynes' study shows gender stereotypes have a profound effect on our brain. Nevertheless, there are some drawbacks. It is difficult to draw conclusions based on small sample size. Although researchers can predict gender stereotypes will occur in sex distribution, the distribution of sexes cannot be determined if a gender stereotype has occurred. Instead, gender stereotypes will exist regardless of sex distribution. For this reason, sample size and gender distribution in the population lack strength. In addition, if the wording cues for job applications change in the next job application, the judgment from the previous situation may not be applicable. I recommended the study could reduce the bias if tracking takes place in laboratory research, but still have different gender groups coming from different backgrounds, such as developing and underdeveloped countries.

\subsubsection{Similarity and difference of workplace gender stereotype}

Previous founding showed gender being categorized, which showed a bias against men and women working in their right fields. According to Guaucher and Friesen (2011), language wording and gender influence a participant's job choices[1]. Moreover, other factors contribute to gender stereotypes as well, such as gender roles being traditionally agreed by most in society, what females and men can do. There are also situations in which there is no clear boundary between men and women in terms of job performance or selection [2]. For instance, in each dominated field, male and female raters have different opinions about their job performance. Although males and females are viewed as controversial, they share the same abilities and talents, no matter what field they specialize in. Even without considering gender, every person has their unique strengths and weaknesses. As an example, adults have more life lessons and slow reactions, but children have fast reactions but lack life lessons. Studies indicate that gender stereotypes frequently appear in occupational conditions because males and females always interact and cooperate to succeed. As an individual, how can we determine who is more successful in the design major if we are placed in a job with a male or female of the same gender, would we consider a female more successful or are women just better in design? Are we seeking personal value, or just looking for successful people with gender differences stereotypically. Considering all the possibilities, it is understandable that the studies may not cover everything. 


\subsection{Academic performance}

\subsubsection{The process and the reason of gender ste- reotype perform academically}

A previous investigation had shown that academic performance with stereotypes was impacted by several factors: belief, self-esteem, and self-efficacy [5]. Each of these reasons has different effects on a person's effort, deep processing, and achievements. Results of the study showed that male and female academic performance differs.

\subsubsection{Gender stereotype with academic perfor- mance in the specific case}

An analysis on how gender stereotypes affect men and women's moral behavior at school [5]. Depending on their gender roles, men and women have different self-esteem. In the study, women tend to score higher on behavioral conduct and morals to indicate higher levels of ethical self-esteem. Even though women have higher ethical and moral awareness than men in this study, that still might not explain why they have higher self-esteem. According to Sapna Cheryan et al., the environment is a cue that impacts a person's interest in computer science [4]. Men and women are positioned in stereotypical or stereotypical environments. Despite the traditional perspective on gender stereotypes, gender stereotypes found in academic performance showed individuals have different cognitive processes of learning. Implicit memory has a relationship with selfconcept in the sense that people value themselves. But deep processing or self-devaluation may not change immediately since it takes a long time to build our selfidentity. The study has limitations in that it presents why women in the same gender have stereotypes but do not show comparisons with males. Therefore, the study may lack an overview of the entire gender group.

\subsubsection{Similarity and current issue with gender stereotype}

Academic performance often displays gender stereotypes similar to occupational stereotypes. Young adults and children can alter their minds earlier when they are presented with new ideas, beliefs, or goals. School is a small society that exhibits both academic competition and stereotypes within these groups. This leads to stereotypes being formed among students. The aim of academic writing in the present day is to ignore gender differences explicitly and to focus on evaluation and interaction with the reader. There is no gender difference in academic writing, but a personal judgment also implicitly conveys their persuasion. However, readers still think that gender differences caused them to contribute self-reference to their statement unconsciously.

\subsection{Autobiographic experience}

Life experiences and early memories were regarded as past experiences with gender stereotypes without considering any culture or historical background. In addition, gender stereotypes about our experiences vary with each individual. Neugarten and his partner found that autobiographical memory has been impacted by life script [9]. Life script refers to a person's life events. Marriage and childbirth are important events in our lives [9]. Another example is the role of parents in teaching their children before they have their understanding of gender [10].

Essentially, parents play a big role in how their children understand gender. Parents' expectations for their children and life events indirectly impact a person's career decisions. According to a person's score in a given subject, autobiographical experience influences academic performance. The stereotypic view women have is that they have less leadership than men, or they score lower in math. The role of parents in guiding children as they explore the world is important, but the process of teaching children how to interact with other children must take into account another possibility as a cue in fostering gender stereotypes.

In addition, how people experience their early childhood with the family has an impact on selfevaluation positively or negatively. A life script is defined by a request for the events of a stereotyped life within a culture. An individual's life story is measured by asking him or her to describe it. A person's memory trail is often related to life experience. People tend to react more to negative memory than positive memory [11]. Some events such as marriage and childbirth are also referred to as life-changing events. Important lifechanging events shaped our interpretations and selfdefining memories. Generally, life events contribute to a person's internal development. Life experience in self-definition and memory about gender stereotypes. Children can be influenced by their parents, but also adults can be influenced by other people since competition exists among them. Therefore, autobiographical experiences affect gender stereotypes.

\subsection{Positive and negative implicit association}

Stereotypes occur in both men and women. Even though people have positive views individually, negative outcomes such as men are less emotional, and women are more irrational. Contrary to implicit stereotypes that are positive and negative. A study reflect more positive associations with intelligence, diligence, and competitiveness [13]. In neutral fields, gender differences favor men's performance, and women's ability is often ignored. It is being seen here as a gender group that regards gender role as a social principle, which eventually leads to gender inequality. Another study by 
Berntsen and Rubin suggests that most of the memories brought to mind by important events are positively influenced [7]. These include graduations, marriages, having children, etc. Stereotypes of a particular gender are one type of stereotype that occurs socially. The distinctions among geographical, national, cultural, and historical locations influence the perspectives of each group of people in society. Likewise, another group unconsciously sees negative stereotypes, while another group unconsciously sees positive stereotypes. Stereotypes are associated with the interpretation of an individual and this identification is linked to a group's social goal without being noticed as positive or negative.

Studies concluded that people are motivated by positive qualities, but not by negative stereotypes. People feel confident about their identity and accept themselves $[14,15]$. Similarly, in another study, women and older people are given separate categories. Older people, women, and mentally handicapped people are stereotyped as high on warmth but low on competence, whereas Jews, Asians, and rich people are stereotyped as low on warmth but high on competence [16]. Unlike stereotypes often describe in negative terms, these studies have shown gender stereotypes within the same gender would develop a different meaning. Although we are aware it is a stereotype undeniably, positive words also encourage people to exhibit this behavior, even in a biased way.

\section{DISCUSSION}

The purpose of the review is to explore how gender stereotype relates to occupational stereotype, academic performance, and autobiographical experience. In a particular environment, self-esteem, or a person's evaluation of themselves, determined the deep level of processing. Several studies have found gender stereotypes in the workplace. For example, comparing the success of men and women in their fields. In situations where there is no male or female dominance, stereotypes are less likely to occur. However, society is changing in the current atmosphere. Three aspects of gender stereotypes, such as social media, social expectations, and living environment might lead to people evaluating themselves differently.

In this review, other aspects of gender stereotypes were not fully covered. Furthermore, there are many possibilities to further explain gender stereotypes, such as social role perspectives, global interactions, and speech perceptions. However, there are some exceptional cases. In the study, the author argues that female stereotypes do occur among female groups, which skewed the overall view of gender stereotypes because the study demonstrated only female stereotype results. Ideally, both male and female stereotypes should be present in the study, otherwise, we can see an unbalance between male and female groups. Therefore, stereo- types occur both interpersonally and socially for both genders. Also, this review raises questions about the future of gender stereotypes in society, will it be beneficial or detrimental to society's development? We have not enacted laws that punish those who hold this stereotype, even those who are thinking explicitly about it, and so there might be uncertain answers. For a writer, it's hard to ignore that people are standing in their position when they view something. Despite our attempts to eliminate the bias in scientific wiring, we overlook the general situation and only minimize the influence of interpersonal beliefs within cultural and experiential contexts. When we think implicitly, the effect may be either emotional, or it may be both. People with emotions wouldn't always stand in the middle ground. However, emotional is another topic to gender stereotypes.

Specifically, the previous research had advantages by investigating how gender is developed in people. Recent studies have shown that gender stereotypes can vary by region, cultural group, social class, etc. This is primarily because the changing of the world has interacted until the present day. In addition, these studies explored the possibility that a gender stereotype may appear in unclear job requirements. Some jobs do not require men or women to perform the "right" tasks, but rather they can perform many types of tasks. Lastly, these studies have found how people currently view each other, but it raises another question; that people might have different perspectives in the future with the combination implicitly or explicitly. Additionally, for real-world applications. To reduce the risks and biases, many experiments included laboratory research, surveying, and biological monitoring methods. For gender stereotype research, self-report (Likert scales or questionaries) and stimulus tests in the lab can be used. Since they are not under our control, they are combined with factors related to history and culture. An evaluation helps to determine how easily participants distort their thinking. Comparing a control group with an experimental group is also beneficial.

\section{CONCLUSION}

In summary, gender stereotypes deal with three aspects: occupational stereotypes, academic performance, and autobiographical experiences. The categories are differentiated from each other by showing how stereotypes can arise in multiple circumstances and how people respond to them when they do. It indicates the issue of geographical predominance, stereotypical cues leading to different thoughts, performing similarly, or individually reminded about the challenges. There are gender stereotypes across the world, and some countries have historically experienced gender inequality in development. Gender stereotypes are most often based on personal experiences without thinking about how peo- 
ple differ. Many of these stereotypes within each field have been combined to form gender stereotypes overall. In future studies, it might give some evidence that people avoid implicit thoughts more explicitly.

\section{REFERENCES}

[1] D. Gaucher, J. Friesen and A. C. Kay, Evidence that gendered wording in job advertisements exists and sustains gender inequality, Journal of personality and social psychology 101(1) (2011) 109. DOI: https://doi.org/10.1037/a0022530

[2] S. B. Morris and R. P. DeShon, Combining effect size estimates in meta-analysis with repeated measures and independent-groups designs, Psychological methods 7(1) (2002) 105. DOI: https://doi.org/10.1037/1082-989X.7.1.105

[3] M. E. Heilman and M. C. Haynes, No credit where credit is due: attributional rationalization of women's success in male-female teams, Journal of applied Psychology 90(5) (2005) 905. DOI: https://doi.org/10.1037/0021-9010.90.5.905

[4] S. Cheryan, V. C. Plaut, P. G. Davies and C. M. Steele, Ambient belonging: how stereotypical cues impact gender participation in computer science, Journal of personality and social psychology 97(6) (2009) $1045 . \quad$ DOI: https://doi.org/10.1037/a0016239

[5] H. P. Phan, Exploring students' reflective thinking practice, deep processing strategies, effort, and achievement goal orientations, Educational Psychology 29(3) (2009) 297-313. DOI: https://doi.org/10.1080/01443410902877988

[6] P. G. Davies, S. J. Spencer, D. M. Quinn and R. Gerhardstein, Consuming images: How television commercials that elicit stereotype threat can restrain women academically and professionally, Personality and Social Psychology Bulletin 28(12) (2002) 1615-1628. DOI: https://doi.org/10.1177/014616702237644

[7] D. Berntsen and D. C. Rubin, Cultural life scripts structure recall from autobiographical memory, Memory \& cognition 32(3) (2004) 427-442. DOI: https://doi.org/

[8] A. Boals, Events that have become central to identity: Gender differences in the centrality of events scale for positive and negative events, Applied Cognitive Psychology: The Official Journal of the Society for Applied Research in Memory and Cognition 24(1) (2010) 107-121. DOI: https://doi.org/10.3758/BF03195836
[9] B. L. Neugarten, J. W. Moore and J. C. Lowe, Age norms, age constraints, and adult socialization, American journal of Sociology 70(6) (1965) 710717. DOI: https://doi.org/abs/10.1086/223965

[10] K. Fuegen, M. Biernat, E. Haines and K. Deaux, Mothers and fathers in the workplace: How gender and parental status influence judgments of jobrelated competence, Journal of Social issues 60(4) (2004) 737-754. DOI: https://doi.org/10.1111/j.0022-4537.2004.00383.x

[11] D. Berntsen and D. C. Rubin, Emotionally charged autobiographical memories across the life span: The recall of happy, sad, traumatic and involuntary memories, Psychology and aging 17(4) (2002) 636. DOI: https://doi.org/10.1037/08827974.17.4.636

[12] M. A. Conway and C. W. Pleydell-Pearce, The construction of autobiographical memories in the self-memory system, Psychological review 107(2) (2000) 261. DOI: https://doi.org/10.1037/0033295X.107.2.261

[13] L. B. Lueptow, L. Garovich-Szabo and M. B. Lueptow, Social change and the persistence of sex typing: 1974-1997, Social forces 80(1) (2001) 136. DOI: https://doi.org/10.1353/sof.2001.0077

[14] P. G. Devine and A. J. Elliot, Are racial stereotypes really fading? The Princeton trilogy revisited, Personality and social psychology bulletin 21(11) (1995) 1139-1150. DOI: https://doi.org/10.1177/01461672952111002

[15] S. Madon, M. Guyll, K. Aboufadel, E. Montiel, A. Smith, P. Palumbo and L. Jussim, Ethnic and national stereotypes: The Princeton trilogy revisited and revised, Personality and social psychology bulletin 27(8) (2001) 996-1010. DOI: https://doi.org/10.1177/0146167201278007

[16] S. T. Fiske, A. J. Cuddy, P. Glick and J. Xu, A model of (often mixed) stereotype content: competence and warmth respectively follow from perceived status and competition, Journal of personality and social psychology 82(6) (2002) 878. DOI: https://doi.org/10.1037/0022-3514.82.6.878

[17] A. G. Greenwald, D. E. McGhee and J. L. Schwartz, Measuring individual differences in implicit cognition: the implicit association test, Journal of personality and social psychology 74(6) (1998) 1464. DOI: https://doi.org/10.1037/00223514.74.6.1464

[18] A. M. Czopp, A. C. Kay and S. Cheryan, Positive stereotypes are pervasive and powerful, Perspectives on Psychological Science 10(4) (2015) 451- 
463.

DOI:

https://doi.org/10.1177/1745691615588091

[19] R. Kahalon, N. Shnabel and J. C. Becker, Positive stereotypes, negative outcomes: Reminders of the positive components of complementary gender stereotypes impair performance in counterstereotypical tasks, British Journal of Social Psychology 57(2) (2018) 482-502. DOI: https://doi.org/10.1111/bjso.12240 